\title{
Positive Thinking \& Good Citizenship Culture: From the Jordanian Universities Students' Points of View
}

\author{
Amani Ghazi Jarrar ${ }^{1}$ \\ ${ }^{1}$ University of Petra, Amman, Jordan \\ Correspondence: Amani Ghazi Jarrar, Assistant Proffessor of Foundations of Education, Faculty of Arts and \\ Sciences, University of Petra, Amman, Jordan. Tel: 962-795-522-401. E-mail: aj8infinity@gmail.com
}

\author{
Received: February 26, 2013 Accepted: March 13, 2013 Online Published: March 25, 2013 \\ doi:10.5539/ies.v6n4p183 URL: http://dx.doi.org/10.5539/ies.v6n4p183
}

\begin{abstract}
This study aims at identifying the nature of the relationship between the mode of thinking among the students of Jordanian Universities if positive, and the extent to which that is related to their culture of citizenship, and therefore their positive practices towards the community. A sample of (654) students were selected randomly. And to achieve the objectives of the study, a questionnaire was developed consisting of (40) items distributed in two areas: culture of good citizenship, and positive thinking. The results showed that Jordanian University students showed a high degree of awareness in the culture of citizenship, and that the level of positive thinking prevailing among the students was high.
\end{abstract}

Keywords: positive thinking, citizenship, Jordanian universities, civic education, teaching thinking skills

\section{Introduction}

We can say that positive thinking about oneself would lead to positive thinking about society; hence the link appears between positive thinking and citizenship in this study. Positive thinking about self-identity means building positive identity, positive expectation, optimism, hope, positive self-talk, and continued positive development. The principles of positive thinking and its applications in the community, include a positive outlook for the community, love for others for their good, taking a positive attitude towards others mistakes, respect for people, and positive interaction with the community.

Here comes the attempt to understand the impact of positive thinking about oneself on positive thinking about society, and therefore of citizenship applications including Provisions of the word based on social, political and educational bases. Many studies address the issue of positive thinking and others address the issue of citizenship, so that this study is trying to link the two issues together, which is studying the impact of positive thinking on the behavior of good citizenship among individuals.

\section{Problem of the Study}

The problem of the study is represented by identifying the nature and patterns of thinking among the students of Jordanian universities, trying to identify how thinking positively affects their awareness of citizenship. The study attempts to detect the gap between the reality and the desired situation of Jordanian university student's patterns of thinking and their awareness of citizenship, in order to understand the thinking and practice problems they have. The study also attempts to detect the degree of positive thinking indicators and positive practices in Jordan Petra University as a sample.

\section{Questions of the Study}

The study raises the following questions:

The first question: What is the prevailing thinking pattern of university students? Is it positive or negative thinking?

Second question: Do positive and negative thinking patterns among students differ according to the variables (gender, specialty of students whether scientific humanitarian, studying a course in civic education, or a course in thinking skills, religious commitment, and intellectual affiliation)?

Third question: To what extent do Jordanian university students acquire a culture of good citizenship? 
And finally the fourth question: Is there any correlation between students' positive thinking and good citizenship?

The study questions handle two areas: The first is a culture of good citizenship which includes a sound understanding of citizenship values and positive practices towards the community, and the second area is positive thinking including standards of positive thinking.

\section{Objectives of the Study}

This study aimed at identifying the nature of the relationship between the thinking patterns of Jordanian university students in correlation with the culture of citizenship and their positive practices towards the community.

\section{The Importance of the Study}

The importance of the study rises when considering the general framework of citizenship as understood by Jordanian university students, whether positive or negative. Educators are usually worried about the students' effective positive thinking that should lead to positive results. Attempts are to develop university students' skills of positive thinking, which is the main headache of the educational system, in spite of the different studies and researches in this area, but still, there appear a lot of questions concerning the best practices to develop these skills. There is also weakness in training programs in this regard, especially in the Jordanian society. Hence the idea of this study is to provide a conceptual framework for Jordanian students to enable them develop their skills of positive thinking, in order to increase effectiveness of their positive thinking skills for the best service possible of their country, reflecting positive practices of good citizenship.

Studies reveal that the greater the confidence in ones' abilities and characteristics of positive thinking, the more positive good practices of citizenship appear. (Brayer ,1999). And that is the goal of universities that should seek in their curriculum that should be covered in drastic courses such as Civic Education and Thinking Skills that have effective impact on positive thinking and good citizenship of university students (Calvert, 2006).

\section{Scope of the Study}

Spatial domain: Petra University as a Jordanian university sample.

Time domain: Questionnaires were distributed in October of the academic year 2011/2012.

\section{Procedural Terminologies}

Positive thinking: The ability and will of an individual to control his/her ideas and beliefs, directing them towards anticipated successful results, and problem-solving through the creating logical optimistic patterns of thinking seeking solving problems. (Ibrahim, 2005)

Good citizenship: The good relationship between the individual and the state as determined by the law of that State, including duties and rights - reciprocal, the status of freedom and responsibilities, and the exercise of the rights in a positive way that benefits the nation. (Nasser, 2001)

\section{Theoretical Literature and Related Studies}

Linguistically, thinking is the realization by the mind of problems trying to reach solutions, and idiomatically, it is defined by Edward De Bono as thoughtful investigation of the experience for certain purposes; it's the effective skill that uses innate intelligence to work.

Positive thinking is to maintain a proper balance in recognizing the various problems, it is an integrated approach to life, focusing on the positive side in any situation, rather than focusing on the negatives, in the sense that we improve very likely, embracing the ideal way of life. According to Scott W., it is that innate ability to reach better results through positive thoughts. (Peiffer, 2002:12).

Positive Thinking is optimistic orientation in life, while negative thinking is pessimistic orientation; it is what leads to success (Neck \&Manz, 1992).

Scientists have classified behavior into three categories: Aggressive or offensive behavior, obedient behavior, or firm behavior and confident. But positive thinking changes results, as the philosopher Plato stated (change your thoughts change your life). Positive thinking affects the self-image, self-esteem, creating a sense of self-acceptance and self-love. It also affects self-confidence. So that John Dewey was one of the first to think as noted in his book (How to think) in 1910,that one should pay attention to be taught how to think (Habib, 1995, p. 9). 
There are, however, four types of energy used by humans when considering something: High positive energy, high negative energy, low positive energy, and low negative energy. All these result in either positive or negative thinking. Since the thoughts make our habits, positive thinking causes the exercise of positive behavior towards issues of good citizenship (Sternberg, 1992, p. 210-219).

So that any change in our lives occurs first within us in the way we think, and that will cause a great revolt of the mind, that makes our lives happier or not (Feqi, 2004, p.17). Positive thinking is the secret of high performance, which enhances openness, honesty and trust, which makes us follow our goals for better future and a better community. (Murphy, 2010, p. 8)

The character traits of those who think positively are: Faith in God, good values like honesty and adaptability, good manners, clear vision, focus on solutions when facing difficulties, taking advantage of challenges and difficulties, changing risks into hope and patience. Positive Thinking is a reflection of goals, efficiently and constructively; it enables us to change life for the better. (Peiffer, 2002, p. 14)

Positive thinking can help into making change using certain strategies, such as: Changing the past, the ideal strategy, the other person's strategy; a strategy that helps us to see things from the other person's point of view, then there is a strategy to change the focus, which serves as an internal evaluation of the experiences of life. There is also the strategy of positive results, which lead us to learn more from failure than we learn from success. One may also use the strategy of redefinition. There is also the supreme value strategy, where it is possible that if the student fails the exam, he/she will learn from that experience to become better next time. Whereas the higher value strategy aims at expanding the horizons of the person so that one can see the value in any challenge, which results into having calm and balanced feelings. There are also the strategic alternatives that enable any person to better handling of challenges .Perhaps the most important commandments of positive thinking are: Taking full responsibility, conscious awareness, goal setting, positive time, self-development, and daily meditation (Johnson, 2002).

Whereas the negative personal qualities that may be caused by negative thinking include the following: Making Causal Inferences, concentration on self (Ego-centralism) which is the absence of the concept of sociality, arrogance, first impression in thinking, which is impulsive decision-making based on the first impression, extremism, generalization as impediments to positive thinking. In addition to (Vacuum), or lack of goals and ambitions. The Halo effect may also result in being bounded to previous idea taken by the individual .That is in addition to (Stereotyping) that may negatively affect our decisions. (Connel, 2004, p. 1)

Positive thinkers may also use self -thought leadership and self-talk strategy through inner power programs that work on recreating peak states away from destructive dialogues used by negative thinkers. (Vocate, 1994)

Positive thinkers use self-organized learning style, which in turn makes them more active and more capable using different strategies in life (Slavin, 1997, p. 87, Butler, 1995, Glaser, 1996) Winston Churchill said once that responsibility towards all our thoughts is the price of greatness, and that if we want to live a life of greater peace, we have to think of ideas more peaceful and of greater goal. (TBenn, 2001, p. 394)

Perhaps our learning style is what mostly affects our thinking and our behavior pattern, and therefore our pattern of citizenship. Kolb defined (1984) methods of learning used by students; two of which are: The assimilator, and the accommodator (p. 259-289).That's why our learning style affects our thinking pattern whether legislative, executive, global, local, liberal, conservative, external, or internal . (Sternberg, 1992, 1994, Grigorenko \& Sternberg, 1995).

As Felder \& Silverman (1988) pointed out in their learning styles being either cognitive, or psychological behaviors. To Myers (1993) criticism ,for example, reflects the positions of thinking, whether positive or negative; they differ according to the following positions : The bilateral position (Duplicity), (Multiplicity), (Relativism), or the position of the obligation (Commitment).These are different positions that maybe taken by students when practicing citizenship behaviors according to their thinking patterns .It can be said that teaching students in university curricula some courses on both (thinking skills) and (civic education) would affect the pattern of thinking they have and therefore their citizenship behaviors.

One can infer from the method of teaching in Jordanian universities how students' practices of citizenship may be according to their patterns of thinking in dealing with different issues. Perhaps the most important foundations of positive thinking and its applications to the community is a positive outlook to the community. Perhaps this is what is meant by good citizenship assuring fundamental values, showing cooperation and positive participation within the society, and discipline. (Covey, 1998, p.200, Tracy, 2007, p. 46) 
Citizenship, which is the second theme of this study, is a controversial concept; it was used historically in both civilizations Greek, Romanian, words as (civis) citizen and (civitash) citizenship, to denote the legal status of the individual. It has four features: identity, virtues, political participation and social requirements of citizenship. Good citizenship means respecting the law, political participation, god awareness of a democratic culture, taking into account positive thinking as a way for developing good citizenship behavior.

Since education is a way to prepare a good citizen, which is complementary to the configuration process in order to achieve social goals, therefore, education of positive thinking is a path to good citizenship. It is known in Socrates philosophy, the study of ethics, politics and humanitarian matters, as explained in his educational philosophy in his book (Politics), where he stresses the state's educational process in order to produce good citizens, where education functions for the development of virtues through formation of good habits emphasizing positive values and positive thinking in building good citizenship (Nasser, 2001, p. 99).

Many studies were conducted in this field, for example Fettes ( 2011) pointed out the importance of civic education for students, allowing them to know their rights and duties; the study concluded that good citizenship lies in the positive impact on the lives of others in the community. Hence, Yaghoubi (2011) showed the positive relationship between good behavior and social intelligence and good citizenship.

Zarghuna \& Ruhi (2010) reviewed the theoretical literature on positive thinking and its impact on the individual behavior of the youth, where the study shows that positive thinking leads to positive feelings and positive behaviors. Another study by Kamel (2010) entitled (Systematic thinking addressing the crisis in the educational knowledge) pointed out the importance of systemic thinking, educational knowledge and positive thinking to make a difference. The study concluded with several recommendations for the preparation of civic education teachers, journalists and religious preachers. The study also recommended the need for more attention to better practices of positive thinking because of its impact on citizens.

Zrzorh (2008) also designed a proposed program to develop good citizenship among students, through the development of a sense of belonging and social responsibility; results of the study has shown that there is a significant correlation between the proposed program in community service and the development of a sense of belonging, and social responsibility of students. Zaff (2008) studied citizenship and challenges of globalization, pointing out its impacts on the values of citizenship, defining also the role of the family in strengthening the values of citizenship, as well as identifying the role that can be played by schools to strengthen the values of citizenship to meet the challenges of globalization. The researcher found the need for intensification of programs enriching values of belongingness and citizenship.

Another study by Abu Hashim (2007) that aim to find out the nature of learning styles and thinking characteristic of students, with a sample of (318) university students, using the learning styles and ways of thinking. The results were a positive correlation between learning styles of learning and ways of students' thinking patterns. Hanray (2007) in his study also tried to identify the impact of the university in teaching students their rights and duties as citizens; he reached a number of results, so that the students' practices in the university and their participation in debates and discussions with teachers, their participation in the issues and problems of society would help them in better understanding of both social and political issues ,so that teaching them in a democratic method contributes in strengthening their values of good citizenship.

In the study conducted by Mnro (2004) to identify the relationship between positive thinking and negative thinking, and the personal optimistic and pessimistic character ; it concluded that there are significant differences in the level of negative and positive thinking attributable to optimistic or pessimistic characters of university students, so that optimistic students have greater level of positive thinking, while pessimists students showed negative thinking patterns; and results showed no effect of gender and specialization variables on the level of positive or negative thinking, and that students mostly tend to be positive in their thinking styles.

Analyzing previous studies that examined positive thinking and good citizenship, some features and basic characteristics of thinking and behavior are subject to analysis, so they were used in the questionnaire designed for this study. Thus the originality of this study appears in the reality of combining patterns of thinking with practices of good citizenship, trying to study the correlation between both variables.

\section{Methodology \& Study Procedures}

This study is a descriptive and analytical study that aims at defining the impact of teaching university students both (Thinking Skills) and (Civic Education) on their values and practices of good citizenship. 


\subsection{The Study Sample}

The study sample consists of students from Petra University as a sample of Jordanian universities. The students selected are those who registered in the first semester of the academic year 2011-2012, representing (654) students from all faculties and levels, taking into consideration only those studying Civic Education and Thinking Skills courses.

\subsection{Study Tool}

The study uses the descriptive approach, where a questionnaire was developed as a tool to collect data covering both areas of positive thinking and good citizenship behavior. The following steps were followed for setting up the scale of the study:

\subsubsection{Stage of Gathering Statements}

The researcher analyzed the theoretical literature related to the subject of positive thinking, and citizenship, focusing on research tools used by former researchers in this area, which include:

- $\quad$ Rights and duties of citizenship measurement tool, designed by Naji, A. (2004)

- Good citizenship characteristics measurement tool, designed by Ahmed, A. (2008).

- Citizenship values according to youth measurement tool, designed by, Saiid, S. (2008).

- The researcher used her practical and academic experience in the development of the scale dimensions, which were represented in two dimensions, then the researcher collected a large number of phrases related to these dimensions, making up (20) statements.

\subsubsection{Assessing the Study Tool and Scale}

The study tool was assessed by (9) professors in the field of education, and in light of their assessment the statements of the measurement were modified, deleting some phrases, and adding others. The result was reaching (20) statements, scaling the statements as responses in five levels (strongly agree, agree, neutral, disagree, strongly disagree).The first scale was given 5 points, while the fifth scale was given 1 point.

\subsubsection{Reliability and Validity}

The questionnaire consists of (20) items classified in two areas of citizenship and positive thinking, the first dimension includes knowledge, understanding, values and practices; the second dimension includes positive perspective towards the self and others, and positive practices towards the community. The questionnaire was modified by academics assessing it by addition or deletion of statements in both dimensions. The study tool was assessed in validity by specialists and experts in Jordanian universities, focusing on the formulation and clarity of paragraphs. According to the opinion of the assessors, the necessary adjustments took place; those phrases that did not get the agreement rate of $75 \%$, from the point of view of the students, were excluded.

The reliability of the tool was verified using Cronbach's $\alpha$ (alpha) equation, where the tool was applied on (50) university students, and after fifteen days, the same measurement was repeated, and according to the students, Pearson correlation was calculated to measure the reliability of the scale, where the correlation for the first dimension was (0.74), and for the second dimension was (0.76).

\subsection{Data Collection Method}

For data collection, the researcher distributed the questionnaire to (750) students, (96) of these were excluded making (13\%) of the total that was accepted reaching (654) making a percentage of $(87 \%)$.

\section{Results and Discussion - Statistical Treatments}

Below is an overview of the most important findings in light of the statistical treatments related to the questions of the study.

\subsection{The First Question: To What Degree the Jordanian Universities Students are Involved in the Culture of Good Citizenship?}

To answer this question the arithmetic means and the standard deviations were calculated, and the classification of paragraphs was in three levels based on the arithmetic means and based on the following criteria:
1) Results less than 2.33 are (Low)
2) Results ranged between 2.34-3.66 are (Average)
3) Results equal and higher than 3.67 are (high) 
Table 1. The arithmetic means and standard deviations for the degree of involvement of the Jordanian Universities students in the culture of good citizenship?

\begin{tabular}{|c|c|c|c|c|}
\hline No & Phrase & $\begin{array}{l}\text { Arithmetic } \\
\text { Mean }\end{array}$ & $\begin{array}{l}\text { Standard } \\
\text { Deviation }\end{array}$ & Level \\
\hline 14 & $\begin{array}{l}\text { I respect human rights and public freedoms of citizens even } \\
\text { if I disagreed with them }\end{array}$ & 4.69 & 0.83 & High \\
\hline 13 & I believe that I have a role in peace in community & 4.57 & 0.82 & High \\
\hline 9 & I stay away from extremism in my community & 4.42 & 1.06 & High \\
\hline 5 & I volunteer to work and serve the community and others & 4.38 & 0.97 & High \\
\hline 10 & I take my Civil and Political responsibilities & 4.32 & 0.97 & High \\
\hline 4 & I believe in the necessity of political participation & 4.26 & 1.02 & High \\
\hline 11 & I practice my freedom to express my thoughts & 4.22 & 1.03 & High \\
\hline 7 & $\begin{array}{l}\text { I have awareness of culture, ideology and the different } \\
\text { schools of thought }\end{array}$ & 4.10 & 1.10 & High \\
\hline 12 & $\begin{array}{l}\text { I respect others regardless of the intellectual and religious } \\
\text { beliefs }\end{array}$ & 4.09 & 0.92 & High \\
\hline 3 & I believe in the values of democracy & 4.08 & 1.17 & High \\
\hline 19 & I argue with others rationally & 3.99 & 0.92 & High \\
\hline 6 & $\begin{array}{l}\text { I participate positively and actively in the issues concerning } \\
\text { public life in my country }\end{array}$ & 3.96 & 1.06 & High \\
\hline 8 & $\begin{array}{l}\text { I respect moral values in dealings with others in the } \\
\text { community }\end{array}$ & 3.86 & 1.08 & High \\
\hline 1 & $\begin{array}{l}\text { Good citizenship ensures obligations, responsibilities and } \\
\text { duties towards the society }\end{array}$ & 3.84 & 0.93 & High \\
\hline 2 & $\begin{array}{l}\text { Good citizen has more affiliation and loyalty in words and } \\
\text { actions. }\end{array}$ & 3.83 & 1.01 & High \\
\hline 18 & I defend national issues with patriotism & 3.82 & 1.05 & High \\
\hline 16 & I respect different cultures and treat others fairly & 3.70 & 1.29 & High \\
\hline 17 & I love my country and I am ready to sacrifice for it & 3.56 & 1.19 & Average \\
\hline 15 & I am committed to law and order in my community & 3.39 & 1.17 & Average \\
\hline \multirow[t]{2}{*}{20} & I believe in the need to maintain order and security & 3.36 & 1.39 & Average \\
\hline & General Average & 4.03 & 1.05 & High \\
\hline
\end{tabular}

Table 1 shows that the arithmetic means of the degree of Jordanian University students involvement in the culture of good citizenship ranged between (3.36-4.69), as the highest value was for the paragraph "I respect human rights and public freedoms of citizens even if I disagreed with them " with the arithmetic mean of (4.69) and deviation standard of (0.83), and lowest value was for the paragraph "I believe in the need to maintain order and security", with the arithmetic mean of (3.36) and with the standard deviation of (1.39). The overall average reached (4.03) and standard deviation (0.38) which is within the high level, so that the degree of Jordanian University students' involvement in the culture of good citizenship was high.

10.2 The Second Question: What is the Prevailing Thinking Level of the Jordanian Universities Students?

To answer this question the arithmetic means and the standard deviations were calculated, and the classification of paragraphs was in three levels based on the arithmetic means and based on the following criteria:

1) Results less than 2.33 are (Low)

2) Results ranged between 2.34-3.66 are (Average)

3) Results equal and higher than 3.67 are (high) 
Table 2. The arithmetic means and standard deviations for the prevailing thinking level among the Jordanian universities students

\begin{tabular}{|c|c|c|c|c|}
\hline No & Phrase & $\begin{array}{l}\text { Arithmetic } \\
\text { Mean }\end{array}$ & $\begin{array}{l}\text { Standard } \\
\text { Deviation }\end{array}$ & Level \\
\hline 10 & I am optimistic and tolerant in my Life actions & 4.35 & 1.02 & High \\
\hline 2 & $\begin{array}{l}\text { I take responsibility for my actions and committed to } \\
\text { improvement }\end{array}$ & 4.32 & 0.85 & High \\
\hline 7 & I like to join others and work in the spirit of the team & 4.24 & 0.93 & High \\
\hline 15 & I don't personalize things and issues & 4.23 & 0.95 & High \\
\hline 11 & $\begin{array}{l}\text { I believe in my ability to change and interact with things } \\
\text { flexibly }\end{array}$ & 4.19 & 0.95 & High \\
\hline 14 & $\begin{array}{l}\text { problems and suffering exist only in a perceptive way and } \\
\text { will take me to what is best }\end{array}$ & 4.19 & 1.02 & High \\
\hline 5 & $\begin{array}{l}\text { In use different thinking patterns in light of what will be } \\
\text { needed }\end{array}$ & 4.16 & 0.95 & High \\
\hline 16 & I feel that I have positive energy to change & 4.07 & 1.06 & High \\
\hline 12 & I can start my own business & 4.06 & 1.03 & High \\
\hline 1 & $\begin{array}{l}\text { I'm trying to solve the problems that I face in life in a } \\
\text { scientific manner }\end{array}$ & 4.03 & 0.94 & High \\
\hline 9 & I'm trying to think outside the box to be more creative & 4.02 & 1.04 & High \\
\hline 19 & I believe that changing ideas creates new reality & 3.94 & 0.97 & High \\
\hline 4 & $\begin{array}{l}\text { I use critical thinking that goes with my thoughts for } \\
\text { community service }\end{array}$ & 3.89 & 1.08 & High \\
\hline 8 & $\begin{array}{l}\text { I'm confident that there is a spiritual solution to my } \\
\text { problems }\end{array}$ & 3.87 & 1.05 & High \\
\hline 17 & $\begin{array}{l}\text { I plan for the future rationally, and learn from the past in } \\
\text { living the present }\end{array}$ & 3.85 & 0.94 & High \\
\hline 3 & Others see that I deal with issues positively & 3.64 & 0.97 & Average \\
\hline 6 & $\begin{array}{l}\text { I believe in my myself and in my ability to change the } \\
\text { society }\end{array}$ & 3.61 & 1.19 & Average \\
\hline 3 & I practice reflective thinking effectively & 3.48 & 1.10 & Average \\
\hline 8 & $\begin{array}{l}\text { I stay away from frustration and inactivity in dealing with } \\
\text { others }\end{array}$ & 3.33 & 1.13 & Average \\
\hline \multirow[t]{2}{*}{20} & I believe that there will always be a better chance coming & 3.33 & 1.30 & Average \\
\hline & General Average & 3.95 & 1.02 & High \\
\hline
\end{tabular}

Table 2 shows that the arithmetic means of the prevailing thinking level among the students of Jordanian Universities ranged between (3.33 -4.45), as the highest value was for the paragraph "I am optimistic and tolerant in my Life actions" with the arithmetic mean of (4.45) and deviation standard of (1.02), and lowest value was for the paragraph "I believe that there will always be a better chance coming" with the arithmetic mean of (3.33) and with the standard deviation of (1.30). The overall average reached (3.95) and standard deviation (1.02) which is within the high level, so that the prevailing thinking level among the students of the Jordanian Universities was high. 
10.3 The Third Question: Is There a Difference in the Level of Positive Thinking among Students according to the Variables (Gender, Nature of the Specialty, Attending the Civic Education Course, Religious Commitment, Attending the Thinking Skills Course, Intellectual Affiliation)?

To answer this question was a $(\mathrm{T})$ test for two independent samples was conducted so as to identify the difference in the levels of positive thinking upon these variables.

\subsubsection{Gender Variable}

Table 3. Test results $(\mathrm{T})$ of the difference in the level of positive thinking among the students of Jordanian Universities according to the gender variable

\begin{tabular}{lccccc}
\hline Gender & Number & Arithmetic Mean & Standard Deviation & T & Significance \\
\hline Male & 118 & 3.95 & 0.50 & 0.21 & 0.83 \\
Female & 100 & 3.94 & 0.46 & 0.20 & 0.84 \\
\hline
\end{tabular}

Table 3 shows that the statistical value $(T)$ was $(0.21)$ which is not functional at the level of $(\alpha=0.05)$ or less. So there is no difference in the level of positive thinking among the students of Jordanian Universities according to the gender variable.

10.3.2 Specialization Variable

Table 4. Test results $(\mathrm{T})$ of the difference in the level of positive thinking among the students of Jordanian Universities according to the specialization variable

\begin{tabular}{cccccc}
\hline Specialization & Number & Arithmetic Mean & Standard Deviation & T & Significance \\
\hline Scientific & 148 & 3.93 & 0.49 & -0.97 & 0.33 \\
Humanitarian & 70 & 3.99 & 0.45 & -1.00 & 0.32 \\
\hline
\end{tabular}

Table 4 shows that the statistical value (T) was $(-0.97)$ which is not functional at the level of $(\alpha=0.05)$ or less. So there is no difference in the level of positive thinking among the students of Jordanian Universities according to the specialization variable.

10.3.3 Attending Civic Education Course Variable

Table 5. Test results (T) of the difference in the level of positive thinking among the students of Jordanian Universities according to Attending Civic Education Course Variable

\begin{tabular}{cccccc}
\hline $\begin{array}{c}\text { Attend Civic } \\
\text { Education Course }\end{array}$ & Number & Arithmetic Mean & $\begin{array}{c}\text { Standard } \\
\text { Deviation }\end{array}$ & T & Significance \\
\hline Yes & 118 & 4.06 & 0.48 & 3.82 & 0.00 \\
No & 100 & 3.82 & 0.45 & 3.84 & 0.00 \\
\hline
\end{tabular}

Table 5 shows that the statistical value (T) was (3.82) which is functional at the level of $(\alpha=0.05)$ or less. So there is a difference in the level of positive thinking among the students of Jordanian Universities according to attending Civic Education Course variable, showing that students who attended the Civic Education Course have a higher level of positive thinking than those who didn't.

\subsubsection{Religious Commitment Variable}

Table 6. Test results (T) of the difference in the level of positive thinking among the students of Jordanian Universities according to the Religious Commitment Variable

\begin{tabular}{cccccc}
\hline $\begin{array}{c}\text { Religious } \\
\text { Commitment }\end{array}$ & Number & Arithmetic Mean & $\begin{array}{c}\text { Standard } \\
\text { Deviation }\end{array}$ & $\mathrm{T}$ & Significance \\
\hline Yes & 139 & 3.96 & 0.49 & 0.35 & 0.73 \\
No & 79 & 3.93 & 0.47 & 0.35 & 0.72 \\
\hline
\end{tabular}


Table 6 shows that the statistical value (T) was $(0.35)$ which is not functional at the level of $(\alpha=0.05)$ or less. So there is no difference in the level of positive thinking among the students of Jordanian Universities according to the Religious Commitment Variable.

\subsubsection{Attending Thinking Skills Course Variable}

Table 7. Test results $(\mathrm{T})$ of the difference in the level of positive thinking among the students of Jordanian Universities according to Attending Thinking Skills Course Variable

\begin{tabular}{cccccr}
\hline $\begin{array}{c}\text { Attend Thinking Skills } \\
\text { Course }\end{array}$ & Number & Arithmetic Mean & $\begin{array}{c}\text { Standard } \\
\text { Deviation }\end{array}$ & T & Significance \\
\hline Yes & 128 & 4.08 & 0.46 & 5.26 & 0.00 \\
No & 90 & 3.76 & 0.45 & 5.27 & 0.00 \\
\hline
\end{tabular}

Table 7 shows that the statistical value (T) was (5.26) which is functional at the level of $(\alpha=0.05)$ or less. So there is a difference in the level of positive thinking among the students of Jordanian Universities according to attending Thinking Skills Course variable, showing that students who attended the Thinking Skills Course have a higher level of positive thinking than those who didn't.

10.3.6 Political Affiliation Variable

Table 8. Test results (T) of the difference in the level of positive thinking among the students of Jordanian Universities according to Political Affiliation Variable

\begin{tabular}{cccccr}
\hline Political Affiliation & Number & Arithmetic Mean & $\begin{array}{c}\text { Standard } \\
\text { Deviation }\end{array}$ & T & Significance \\
\hline Yes & 98 & 3.94 & 0.51 & -0.24 & 0.81 \\
No & 120 & 3.95 & 0.46 & -0.24 & 0.81 \\
\hline
\end{tabular}

Table 8 shows that the statistical value (T) was $(-0.24)$ which is not functional at the level of $(\alpha=0.05)$ or less. So there is no difference in the level of positive thinking among the students of Jordanian Universities according to Attending Political Affiliation Course Variable.

10.4 The Fourth Question: Is There a Correlation between the Level of Positive Thinking and Good Citizenship among the Students of Jordanian Universities?

To answer this question Pearson's correlation coefficient of the relationship between the level of positive thinking and good citizenship among the students of Jordanian universities were calculated as shown in Table 9.

Table 9. Pearson Correlation Coefficient between the level of positive thinking and good citizenship among the students of Jordanian Universities

\begin{tabular}{cc}
\hline Correlation Coefficient & Significance \\
\hline 0.3 & 0.001 \\
\hline
\end{tabular}

Table 9 shows that the Correlation Coefficient between the level of positive thinking and good citizenship among the students of Jordanian Universities reached (0.30), which is functional at the level of $(\alpha=0.05)$ or less, so there is a correlation between the level of positive thinking and good citizenship among the students of Jordanian Universities.

\section{Conclusion \& Recommendations}

Having reached those results, the following can be concluded and recommended: civic education as a compulsory course mandatory, which is to be a pre-requirement for graduation. Professors should also link the previous two courses as of two dimensions (theoretical or intellectual, and practical or behavioral), so that students should be fully aware of the link between civic education course and thinking skills course. More care should be given to training of university students on the methods of positive thinking, clarifying its impact on practices of good citizenship through open dialogue, problem-solving, and constructive criticism for the good of 
others and the society. To fulfill that universities should add credit hours as a requirement for graduation, considering that as for (direction and guidance), so that the professors can make psychologically direction and counseling for all students to enable them to exercise positive thinking and solve their problems in life, instructing them to better practices for their good and their community.

\section{References}

Ahmed, R. (2008). The basis of positive thinking and its applications toward self and society. International Conference on Community Development: Challenges and Prospects, Islamic University of Malaysia. (Arabic resource).

Brayer, B. (1999). Development a scope and sequence for thinking skills instruction". Educational leadership, 45(7), 244-271.

Butler, D., \& Winne, P. (1995). Feedback and Self-Regulated Learning: A Theoretical Synthesis. Review of Educational Research, 65(3), 245-281.

Calvert, R. (2006). To Restore American Democracy Political Education and the modern university. Roman and little Field Education. USA.

Connel, J. (2004). Stress News, Person Center Counseled in Working with Stress Problems, 16(1).

Covey, S. (1998). The Seven Habits (2nd ed.). Translated edition .The Arab Institution for Studies, Beirut.

Felder, R., \& Silverman, L. (1988). learning and teaching styles in engineering education. Journal of Engineering Education, 78(7).

Feqi, I. (2004). The power of self-control (2nd ed.). Foundation of Smart Step, Jeddah. (Arabic resource).

Glaser, R. (1996). Assessment and Education Access and Achievement. Paper Presented at the Annual Meeting of American Education al Research association, New York.

Grigorenko, E., \& Sternberg, R. (1995). Styles of thinking in the school. European Journal for High Ability, 6.

Habib, M. (1995). Studies in ways of thinking. Cairo, Egyptian Renaissance for publication. (Arabic resource).

Hanray, M. (2007). Citizenship in colleges an introduction to effective practice. Learning and skills network, United States.

Ibrahim, A. (2005). The effectiveness of positive thinking program for students under psychological pressure. Journal of Education, College of Ismailia, Suez Canal University. (Arabic resource).

Johnson, F. (2002). Negative thinking the opposite of positive thinking: Which are you more likely to identify with? Leading Facts, Inc, 12(14).

Kamel, A. (2010). Systematic thinking addressing the crisis in educational knowledge. Conference on contemporary educational knowledge: Egypt as a model, Center for Cognitive Studies, Cairo. (Arabic resource).

Kolb, D. (1984). Experiential Learning Experience as the Source of Learning and Development. London, Prentice-Hall International, Inc.

Mnro, K. (2004). Optimism: How to avoid negative thinking. www.KaliMunro.com.

Murphy, T. (2010). Conversations on engaged pedagogies, independent thinking skills and active citizenship. Issues in Educational Research, 20(1), 39-46.

Myers, C. (1993). Teach students critical thinking. (Translated edition by Azmi Jarrar). Amman: Jordan, books' Center.

Naji, A. (2004). University student's perceptions of citizenship rights and duties. Scientific Conference XV, Faculty of Social studies, University of Fayoum, held in 10 - 11 May. (Arabic resource).

Nasser, I. (2001). Philosophies of education (1st ed.). Amman: Dar Wael for Publication. (Arabic resource).

Neck, C., \& Manz, C. (1992). Thought Self-leadership: The Influence of Self-Talk \& Mental Imagery on Performance. Journal of Organizational Behavior, 13, 681-699. http://dx.doi.org/10.1002/job.4030130705

Peiffer, V. (2002). Positive Thinking: Everything you have always known about positive thinking but were afraid to put into practice (2nd ed.), Harper Collins, London.

Saiid, H. (2008). The role of family in development of citizenship values of young people in light of globalization challenges, Scientific Forum for Saudi families contemporary changes, Saudi Society for 
Sociology, University of Imam Muhammad bin Saud Islamic University, Saudi Arabia, pp. 188-189, (Arabic resource).

Slavin, R. (1997). Educational Psychology Theory and Practice (5th ed.). London, Allyn \& Bacon. P. 87.

Sternberg, R. (1992). Thinking styles: Theory and assessment at the interface between intelligence and personality. New York: Cambridge University press.

Sternberg, R. (1994). Allowing for thinking styles. Educational Leadership, 52(3), 36-40.

TBenn et al. (2001). Churchill Remembered: Recollections by Tony Benn MP, Lord Carrington, Lord Deedes and Mary Soames. Journal of Transactions of the Royal Historical Society, 11, 393-414.

Tracy, B. (2007). Change your mind change your life (1st ed.). Translated edition, Jarir Bookstore, Riyadh.

Vocate, D. (1994). Self-Talk\& Inner Speech Understanding the Uniquely Human Aspects of Interpersonal Communication. Chapter (2), Hillsdale N. J. US: Erlbaum Association.

Yaghoubi et al., (2011). An Analysis of Correlation between Organizational Citizenship Behavior (OCB) and Emotional Intelligence (EI). Journal of Modern Applied Science, 5(2), 119-123.

Zaff, et al., (2008). Predicting Positive Citizenship from Adolescence to Young Adulthood: The Effects of a Civic Context. Journal of Applied Developmental Science, 12(1), 38-53. http://dx.doi.org/10.1080/10888690801910567

Zarghuna, N., \& Ruhi, K. (2010). Positive Thinking in Coping with Stress and Health outcomes: Literature Review. Journal of Research \& Reflections in Education (JRRE), 4(1), 42-61. 